\title{
Optimum dosage of 5-aminosalicylic acid as rectal enemas in patients with active ulcerative colitis
}

\author{
M Campieri, P Gionchetti, A Belluzzi, C Brignola, M Tampieri, P Iannone, \\ M Miglioli, L Barbara
}

\begin{abstract}
5-Aminosalicylic acid (5-ASA), the active moiety of sulphasalazine (SASP), was given as a rectal enema to patients with mild to moderate distal ulcerative colitis to determine the minimum effective dosage. A double blind study was carried out using enemas containing 1,2 , or $4 \mathrm{~g}$ or 5-ASA or placebo for a one month treatment period. One hundred and thirteen patients with ulcerative colitis attending our outpatient clinic volunteered to participate. Clinical, sigmoidoscopic, and histological assessments were carried out at the beginning of the study and after 15 and 30 days of treatment. All patients who received 5-ASA enemas showed significantly better results than those who received a placebo enema $(p<0.001)$ but no difference was detected among the patients receiving differing concentrations of 5-ASA. This study suggests that $1 \mathrm{~g}$ 5-ASA (in a $100 \mathrm{ml}$ enema) is a sufficient dosage for patients with a mild to moderate attack of ulcerative colitis.
\end{abstract}

It has been well established for more than 10 years that sulphasalazine (SASP) works only through one of its components, 5-aminosalicylic acid (5-ASA), which is beneficial through its topical action..$^{1-3}$ Because of this, rectal enemas containing 5-ASA have become a first line treatment for patients with mild or moderate attacks of left sided ulcerative colitis. ${ }^{46}$ Clinical trials have been carried out using different dosages of 5-ASA in enemas. In the first of these studies, designed to detect the active moiety of SASP, Azad Khan et al ${ }^{1}$ used $700 \mathrm{mg}$ only, which corresponds to the dosage of 5-ASA released in the colon by $2 \mathrm{~g}$ of SASP taken orally. Their positive results were equal to those obtained with enemas containing $2 \mathrm{~g}$ of SASP.

We subsequently adopted 5-ASA at very high dosages $(4 \mathrm{~g}),{ }^{4}$ believing that the benefits would be dose related, as they are for oral SASP. ${ }^{7}$ The results obtained were extremely good and the high dosages of 5-ASA given by rectum did not produce the unwanted effects associated with an equivalent dosage of 5-ASA linked to sulphapyridine given orally. ${ }^{8}$ In the following years there have been further studies using 5-ASA given at dosages ranging from $1 \mathrm{~g}$ to $4 \mathrm{~g}^{569}$ and the results have always been satisfactory. Since the study design was different in each trial, however, it was not possible to compare the data and to establish the lowest dosage with the maximum benefit.

Powell-Tuck et al used enemas containing either 1 or $2 \mathrm{~g}$ of 5-ASA in a small pilot study ${ }^{10}$ but they were unable to find a dose-response benefit.
Since it is not possible to rule out the possibility that a higher dosage such as $4 \mathrm{~g}$ could provide a better response, we designed this prospective double blind clinical trial to compare the efficacy of three different dosages of 5-ASA enemas (1, 2 , or $4 \mathrm{~g}$ ) currently available in commercial preparations and placebo enemas.

\section{Patients and methods}

This trial was designed as a four week randomised double blind placebo controlled study. The protocol was reviewed and approved by the board of senior clinicians of our department. Altogether 113 consecutive patients with mild to moderate ulcerative colitis that did not extend beyond the splenic flexure (confirmed by colonoscopy) volunteered to take part in the study after having been fully informed about the nature and the purpose of the trial. All the patients who entered the trial were outpatients aged more than 18 years. During the study, no rectal or systemic steroid medications were allowed. Patients with hepatic or renal dysfunction were excluded.

Patients were randomly allocated to receive $100 \mathrm{ml}$ enemas containing $1 \mathrm{~g}, 2 \mathrm{~g}$ or $4 \mathrm{~g}$ of 5 -ASA or placebo for 30 days. They were divided into two groups according to whether or not they were already on maintenance treatment with oral SASP ( $2 \mathrm{~g}$ daily). Clinical, sigmoidoscopic, and histological examinations were performed before entry to the trial and after 15 and 30 days of treatment. The grading of clinical, sigmoidoscopic, and histological disease activity was defined according to Truelove and Richards criteria."

For the clinical assessment we recorded stool frequency, rectal bleeding, presence of mucus, abdominal pain, and relevant symptoms while with an endoscopic examination we investigated hyperaemia, granularity, petechiae, fragility, contact or spontaneous bleeding and ulceration. For histological assessment, a rectal biopsy specimen was taken from the posterior rectal wall (from a standard location between 5 and $10 \mathrm{~cm}$ from the anus) and was examined for oedema, inflammatory infiltrate, crypt abscess, mucus depletion, gland architecture, and ulceration. The clinical and sigmoidoscopic assessments were made by the same 'blind' investigators throughout the study. The histological examination was done separately in the department of pathological anatomy.

The patients were judged clinically, sigmoidoscopically, and histologically improved when there was at least one grade of reduction in activity according to the criteria adopted. They were considered in clinical remission when the symptoms of active disease resolved. In sigmoid- 
TABLE I Patients' characteristics

\begin{tabular}{|c|c|c|c|c|}
\hline \multirow[b]{2}{*}{ Type of treatment } & \multicolumn{3}{|l|}{ 5-ASA } & \multirow[b]{2}{*}{ Placebo } \\
\hline & $\lg$ & $2 g$ & $4 g$ & \\
\hline No of patients & 27 & 30 & 29 & 27 \\
\hline Male/female & $13 / 14$ & $12 / 18$ & $13 / 16$ & $15 / 12$ \\
\hline Age, mean (yrs) & 36 & & & \\
\hline \multicolumn{5}{|l|}{ Extent of disease: } \\
\hline Proctitis & 7 & 10 & 8 & 8 \\
\hline Proctosigmoiditis & 8 & 9 & 12 & 10 \\
\hline Left-sided colitis & 12 & 11 & 9 & 9 \\
\hline \multicolumn{5}{|l|}{ Clinical activity: } \\
\hline Moderate & 15 & 16 & 16 & 15 \\
\hline Mild & 12 & 14 & 13 & 12 \\
\hline \multicolumn{5}{|c|}{ Sigmoidoscopic appearance: } \\
\hline Grade 3 & 6 & 8 & 8 & 7 \\
\hline Grade 2 & 12 & 12 & 14 & 11 \\
\hline Grade 1 & 9 & 10 & 7 & 9 \\
\hline \multicolumn{5}{|c|}{ Histological appearance: } \\
\hline Grade 3 & 9 & 10 & 9 & 9 \\
\hline Grade 2 & 11 & 12 & 12 & 11 \\
\hline Grade 1 & 7 & 8 & 8 & 7 \\
\hline
\end{tabular}

5-ASA = 5-aminosalicylic acid.

oscopic remission, the rectal mucosa was repaired, with the appearance of a vascular pattern. In histological remission the mucosa had no signs of active inflammation. The haematological parameters were assessed before and after the treatment period. Stool examination excluded the presence of pathogens. Statistical analysis was performed using the $\chi^{2}$ test.

\section{ENEMA FORMULATIONS}

The basic vehicle for the enemas comprised sodium carboxymethylcellulose ( $1 \mathrm{~g}$ ), sodium dihydrogen phosphate dodecaidrate $(0 \cdot 125 \mathrm{~g})$, sodium chloride $(0.9 \mathrm{~g})$, ascorbic acid (as sodium salt) $(0.05 \mathrm{~g})$, gum tragacanth $(0.4 \mathrm{~g})$, and water to reach $100 \mathrm{ml}$ of volume.

One, 2, or $4 \mathrm{~g}$ of purified 5-ASA were put in sealed containers containing $0.01 \mathrm{~g}, 0.015 \mathrm{~g}$, and $0.03 \mathrm{~g}$ of sodium carboxymethylcellulose. The placebo enemas were prepared similarly. In order to ensure the 'blindness' of the study, 0.35 $g$ of lactose (a white powder very similar to the pure 5-ASA) was also placed in containers. The contents of each container were mixed by each patient with the basic vehicle just before use.

The enemas were provided by CHIESI Pharmaceutical Company, Parma, Italy.

\section{Results}

The baseline characteristics of patients are given in Table I. The groups were comparable with regard to age and sex distribution, duration of disease, and disease activity.

All the patients completed the study. Only five complained of minor troubles - two in the placebo group and one for each 5-ASA group. These effects were not drug related. Haematological and biochemical tests were within the normal range and stool examinations were negative for pathogens.

Table II gives the clinical, sigmoidoscopic, and histological outcomes after 15 and 30 days of treatment. The results are reported separately for each group and as overall data.

In each of the 5-ASA treated groups, there was a clear beneficial effect related to the nightly enema administration that was significantly better $(p<0.001)$ than that obtained in the placebo group. This positive effect was observed clinically, sigmoidoscopically, and histologically. With regard to the clinical outcome, in the group treated with $1 \mathrm{~g}$ 5-ASA enemas, 21 of $27(78 \%)$ improved or were in remission after 15 days and 23 of 27 (85\%) after 30 days. In the group treated with $2 \mathrm{~g}$ 5-ASA enemas, 23 of 30 (77\%) after 15 days and 25 of $30(83 \%)$ after 30 days improved or were in remission. In the group treated with $4 \mathrm{~g}$ enemas, 24 of $29(83 \%)$ after 15 days and 25 of $29(86 \%)$ after 30 days were improved or in remission. The figures for the placebo group are 10 of $27(37 \%)$ and 11 of 27 (41\%) after 15 and 30 days respectively.

With regard to the sigmoidoscopic findings, after 15 and 30 days the percentages of patients improved or in remission were $67 \%$ and $74 \%$, $67 \%$ and $73 \%, 76 \%$ and $79 \%, 26 \%$ and $30 \%$ for $1 \mathrm{~g}, 2 \mathrm{~g}$, and $4 \mathrm{~g} \mathrm{5-ASA}$ enemas and placebo respectively.

The percentages showing histological improvement after 15 and 30 days' treatment were $55 \%$ and $63 \%$ for $1 \mathrm{~g} 5$-ASA, $63 \%$ and $70 \%$ for $2 \mathrm{~g} \mathrm{5-ASA}, 69 \%$ and $76 \%$ for $4 \mathrm{~g} \mathrm{5-ASA}$, and $11 \%$ and $15 \%$ for placebo.

With regard to all the parameters evaluated, there were no statistical differences between the three groups given 5-ASA enemas. Table II shows a slightly better (statistically insignificant)

TABLE II Clinical, sigmoidoscopic, and histological outcome in patients with active ulcerative colitis treated with 5-aminosalicylic acid (5-ASA) enemas or placebo

\begin{tabular}{|c|c|c|c|c|c|c|c|}
\hline \multirow[b]{2}{*}{ Type of enema } & \multirow[b]{2}{*}{ No } & \multicolumn{2}{|c|}{ No improved clinically } & \multicolumn{2}{|c|}{ No improved sigmoidoscopically } & \multicolumn{2}{|c|}{ No improved histologically } \\
\hline & & $15 d y s$ & 30 dys & $15 d y s$ & $30 d y s$ & $15 d y s$ & 30 dys \\
\hline \multicolumn{8}{|l|}{ No maintenance } \\
\hline lg 5-ASA & 12 & $9(\mathbf{R}=4)$ & $10(R=8)$ & $7(\mathbf{R}=3)$ & $8(R=5)$ & $6(\mathrm{R}=2)$ & $7(\mathbf{R}=4)$ \\
\hline $2 \mathrm{~g} 5$-ASA & 14 & $11(\mathbf{R}=5)$ & $12(\mathbf{R}=10)$ & $9(\mathrm{R}=4)$ & $10(R=6)$ & $8(\mathrm{R}=3)$ & $9(\mathrm{R}=6)$ \\
\hline $4 \mathrm{~g} 5$-ASA & 13 & $11(\mathbf{R}=6)$ & $12(\mathbf{R}=10)$ & $10(\mathbf{R}=5)$ & $11(\mathbf{R}=7)$ & $9(\mathrm{R}=4)$ & $10(\mathrm{R}=6)$ \\
\hline Placebo & 13 & $4(\mathrm{R}=0)$ & $4(\mathrm{R}=1)$ & $3(\mathbf{R}=0)$ & $4(\mathrm{R}=1)$ & $1(\mathbf{R}=0)$ & $2(\mathbf{R}=0)$ \\
\hline \multicolumn{8}{|c|}{$\begin{array}{l}\text { Maintenance } \\
\text { treatment with SASP }\end{array}$} \\
\hline $\begin{array}{l}\text { treatment wit } \\
2 \mathrm{~g} / \text { daily }\end{array}$ & & & & & & & \\
\hline 1 g 5-ASA & 15 & $12(R=5)$ & $13(\mathbf{R}=9)$ & $11(R=4)$ & $12(R=7)$ & $9(\mathrm{R}=3)$ & $10(R=6)$ \\
\hline $2 \mathrm{~g} 5$-ASA & 16 & $12(\mathrm{R}=6)$ & $13(\mathrm{R}=10)$ & $11(\mathbf{R}=5)$ & $12(\mathrm{R}=7)$ & $11(\mathrm{R}=4)$ & $12(\mathrm{R}=7)$ \\
\hline $4 \mathrm{~g} 5$-ASA & 16 & $13(\mathbf{R}=7)$ & $13(\mathrm{R}=11)$ & $12(\mathbf{R}=6)$ & $12(\mathrm{R}=8)$ & $11(R=4)$ & $12(R=7)$ \\
\hline $\begin{array}{l}\text { Placebo } \\
\text { Ploce }\end{array}$ & 14 & $6(\mathrm{R}=1)$ & $7(\mathbf{R}=2)$ & $4(\mathrm{R}=1)$ & $4(\mathrm{R}=1)$ & $2(\mathbf{R}=0)$ & $2(\mathrm{R}=0)$ \\
\hline \multicolumn{8}{|l|}{ Overall results } \\
\hline & & $21(\mathrm{R}=9)^{\star}$ & $23(\mathbf{R}=17)^{\star}$ & $18(R=7)^{\star}$ & $20(R=12)^{\star}$ & $15(\mathrm{R}=5)^{\star}$ & $17(\mathrm{R}=10)^{\star}$ \\
\hline $2 \mathrm{~g} 5$-ASA & 30 & $23(\mathbf{R}=11)^{\star}$ & $25(\mathbf{R}=20)^{\star}$ & $20(R=9)^{\star}$ & $22(\mathbf{R}=13)^{\star}$ & $19(\mathrm{R}=7)^{\star}$ & $21(\mathrm{R}=13)^{\star}$ \\
\hline $4 \mathrm{~g} 5$-ASA & 29 & $24(R=13)^{\star}$ & $25(\mathbf{R}=21)^{\star}$ & $22(\mathbf{R}=11)^{\star}$ & $23(\mathrm{R}=15)^{\star}$ & $20(\mathrm{R}=7)^{\star}$ & $22(\mathrm{R}=12)^{\star}$ \\
\hline Placebo & 27 & $10(\mathbf{R}=1)^{\star}$ & $11(\mathrm{R}=3)$ & $7(\mathbf{R}=1)$ & $8(\mathrm{R}=2)$ & $3(\mathrm{R}=0)^{\star}$ & $4(\mathrm{R}=0)$ \\
\hline
\end{tabular}

${ }^{\star} \mathrm{p}<0.01$ in comparison with placebo. $R=$ remission. 
histological response in the group given $4 \mathrm{~g}$ 5-ASA enemas. The overall outcome was not influenced by the maintenance treatment with SASP.

\section{Discussion}

This double blind placebo controlled trial was designed to establish the optimum therapeutic dosage of 5-ASA enemas in the treatment of patients with mild to moderate left sided colitis. Three different 5-ASA enema preparations (containing 1,2 , and $4 \mathrm{~g}$ ) were used, while another group of patients was treated with placebo enemas.

Our results clearly indicate that all the 5-ASA treated patients showed significantly better results than those treated with placebo. These data confirm the value of the topical administration of 5-ASA enemas for distal ulcerative colitis as suggested in previous studies. ${ }^{46}$.

No statistical differences were detected between the various subgroups of 5-ASA treated patients, so it seems that the topical administration of 5-ASA enemas does not produce a dose dependent therapeutic effect. The findings of this study agree with a previous preliminary study ${ }^{10}$ carried out to investigate a possible dosedependent effect of 5-ASA administered as rectal enemas. In our study, the results obtained using a dosage of $4 \mathrm{~g}$ further confirm the already postulated lack of a dose-response effect reported with only two 5-ASA preparations ( 1 and $2 \mathrm{~g}$ ). What was speculatively suggested by extrapolating the results of a small pilot study ${ }^{10}$ is substantiated by the data from our prospective controlled study.

The question that needs clarification is why the topical rectal administration of 5-ASA, either as an enema or suppository, ${ }^{12}$ does not produce a dose dependent therapeutic effect when at least two studies have shown that oral 5-ASA preparations are effective in a dose dependent way. ${ }^{13-14}$ One possible explanation of these contrasting findings could be related to the different distribution of 5-ASA in the colon. Because the active component in the enemas is administered straight to the inflamed region a therapeutic tissue concentration can be reached even at relatively low dosages.

When 5-ASA is given orally there is variable intestinal absorption due to the various mechanisms of liberation of 5-ASA from its different oral preparations. ${ }^{15}$ Furthermore 5-ASA is distributed to the whole colon so it could not reach the same concentrations in the rectosigmoid area as for rectal formulations. This might explain why $1 \mathrm{~g}$ of 5-ASA in $100 \mathrm{ml}$ enemas is a sufficient and effective dosage. These data indicate that low dosages of 5-ASA can be given in enemas, obviating the administration of unnecessarily large quantities of this drug to patients with distal colitis. Since 1 g 5-ASA enemas give prompt and effective treatment for patients with left sided colitis and much higher dosages are necessary to obtain similar results with oral formulations of the drug, the former should be the first choice treatment in patients with ulcerative colitis limited to the left colon.

Nevertheless, our study does not exclude the possibility that dosages even lower than $1 \mathrm{~g}$ could be as effective and this should be investigated in a clinical trial. Since enemas containing $1 \mathrm{~g}$ of 5-ASA have been shown to produce negligible plasma concentrations, however, ${ }^{16}$ this problem is not of primary clinical importance.

1 Azad Khan AK, Piris J, Truelove SC. An experiment to determine the active therapeutic moiety of sulphasalazine. determine the active

2 Van Hees PAM, Bakker JH, Van Tongern JHM. Effect of sulphapiridine, 5 -aminosalicylic acid and placebo in patients with idiopathic proctitis: a study to determine the active therapeutic moiety of sulphasalazine. Gut 1980; 21: 632-5.

3 Klotz U, Maier K, Fischer C, Heikel K. Therapeutic efficac of sulphasalazine and its metabolites in patients with ulcerative colitis and Crohn's disease. $N$ Engl F Med 1980; 303: 1499-502.

4 Campieri M, Lanfranchi GA, Bazzocchi G, et al. Treatment of ulcerative colitis with high-dose 5-aminosalicylic acid enemas. Lancet 1981; ii: 270-1.

5 Danish 5-ASA group. Topical 5-aminosalicylic acid versus prednisolone in ulcerative proctosigmoiditis. A randomized prednisolone in ulcerative proctosigmoiditis. A randomized 602 .

6 Sutherland LR, Martin F. 5-aminosalicylic acid enemas in the maintenance of remission in distal ulcerative colitis and proctitis. Can f Gastroenterol 1987; 1: 3-6.

7 Azad Khan AK, Howes DT, Piris J, Truelove SC. Optimum dose of sulphasalazine for maintenance treatment in ulcera tive colitis. Gut 1980; 21: 232-40.

8 Truelove SC, Watkinsons G, Draper G. Comparison of corticosteroid and sulphasalazine therapy in ulcerative colitis $B M 7$ 1962; ii: 1708-11.

9 Willoughby CP, Campieri M, Lanfranchi GA, et al. 5-aminosalicylic acid (Pentasa) in enema form for the treatment of active ulcerative colitis. Ital $\mathcal{f}$ Gastroenterol treatment of activ

10 Powell-Tuck J, MacRae K, Healy MJR, Lennard-Jones JE, Parkins RA. A defence of the small clinical trial: evaluation of three gastroenterological studies. BMF 1986; 92: 599602 .

11 Truelove SC, Richards WCD. Biopsy studies in ulcerative colitis. BMF 1956; i: 1315-7.

12 Campieri M, De Franchis R, Bianchi Porro G, Ranzi P Brunetti G, Barbara L. Mesalazine (5-aminosalicylic acid) suppositories in treatment of ulcerative proctitis or dista suppositories in treatment of ulcerative proctitis or distal

13 Miglioli M, Bianchi Porro G, Sturniolo G, Brunetti G, Italian Miglioli M, Bianchi Porro G, Sturniolo G, Brunetti G, Italian of mild ulcerative colitis: a dose ranging study. Europ $\mathcal{f}$ Gastroent Hepatol 1990; 2 (3): 229-34.

14 Hanauer S, Schwartz J, Roufail W, Robinson M, Cello J, Safdi $M$, Guernsey B, Beshears L. Dose-ranging study of oral mesalamine capsule (Pentasa) for active ulcerative colitis. Gastroenterology 1989; 96 (5): A195.

15 Rijk MC, Van Hogezand RA, Van Schaik A, Van Tongeren JHN. Disposition of 5-aminosalicylic acid from 5-aminosalicylic acid-delivering drugs during accelerated intestinal transit in healthy volunteers. Scand $\mathcal{F}$ Gastroenterol 1989; 24: 1179-85.

16 Bondesen $S$, Haagen Nielsen $O$, Jacobsen $O$, Norby Rasmussen S, Honoré Hansen S, Halskov S, Binder V, Hvidberg EF. 5-Aminosalicylic acid enemas in patients with active ulcerative colitis. Influence of acidity on the kinetic pattern. Scan $\mathcal{F}$ of Gastroenterol 1984; 19: 60-5 